Recent Advances in Communication, Electronics \& Electrical Engineering

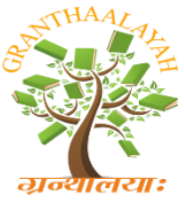

INTERNATIONAL JOURNAL OF RESEARCH -

RACEEE - 17

\title{
A SURVEY ON AUTONOMUS CAR TESTING
}

\author{
Manasa $\mathbf{S}^{1}$, Lekhana $\mathbf{N}^{2}$, Prof. Krishnananda ${ }^{3}$ \\ 1,2,3 Electronics \& Communication Department, Dayananda Sagar College of Engineering, \\ Bangalore, India
}

DOI: https://doi.org/10.29121/granthaalayah.v5.i4RACEEE.2017.3321

\begin{abstract}
Amid self-governing auto framework improvement, the independent vehicles testing directions build up a Self-sufficient Vehicle Analyzer Program with sensors and control framework. In this paper, the overview of the independent auto, sorts of sensors and control framework is presented. The LiDAR, Radar and GPS capacities are reached out into self-sufficient auto testing. Additionally, the mileage, benefits and restrictions are examined. Time and cost can be saved and a more solid framework can be ensured.
\end{abstract}

Keywords: LiDAR; Radar; GPS; Camera; Control Systems.

Cite This Article: Manasa S, Lekhana N P, and Prof. Krishnananda. (2017). "A SURVEY ON AUTONOMUS CAR TESTING." International Journal of Research - Granthaalayah, 5(4) RACEEE, 42-47. https://doi.org/10.29121/granthaalayah.v5.i4RACEEE.2017.3321.

\section{Introduction}

Individuals drive their autos to work, for shopping, to visit their companions and to numerous different spots. Youngsters like to take the transport to class. The economy depends to a great extent on the merchandise that is conveyed by trucks. This versatility is typically underestimated by a great many people and they scarcely understand that transportation shapes the premise of our progress. As the urban areas develop and the populace expands, more activity is created which has numerous antagonistic impacts. The requirement for a more effective, adjusted and more secure transportation framework is self-evident. This need can be best met by the usage of independent transportation frameworks. The future vehicles will be fit for deciding the best course and caution each other about the conditions ahead.

Many organizations and establishments are cooperating in innumerable tasks with a specific end goal to actualize the savvy vehicles like Self-governing Autos and transportation systems without bounds. 
Recent Advances in Communication, Electronics \& Electrical Engineering

In spite of the fact that the opposition in self-ruling auto innovation has warmed up extensively in the course of the most recent 2 years, most industry specialists keep on expecting a moderate selection bend which could without much of a stretch traverse a few decades.

A self-sufficient vehicle is on a very basic level characterized as a traveler vehicle that drives without anyone else. A self-governing vehicle is additionally alluded to as an autopilot, driverless auto, auto-drive auto, or Computerized Guided Vehicle (AGV). Most models that have been manufactured so far performed programmed guiding that depended on detecting the painted lines in the street or attractive monorails inserted in the road.

Today's scientists are utilizing sensors and propelled programming together with other handcrafted equipment to amass independent autos.

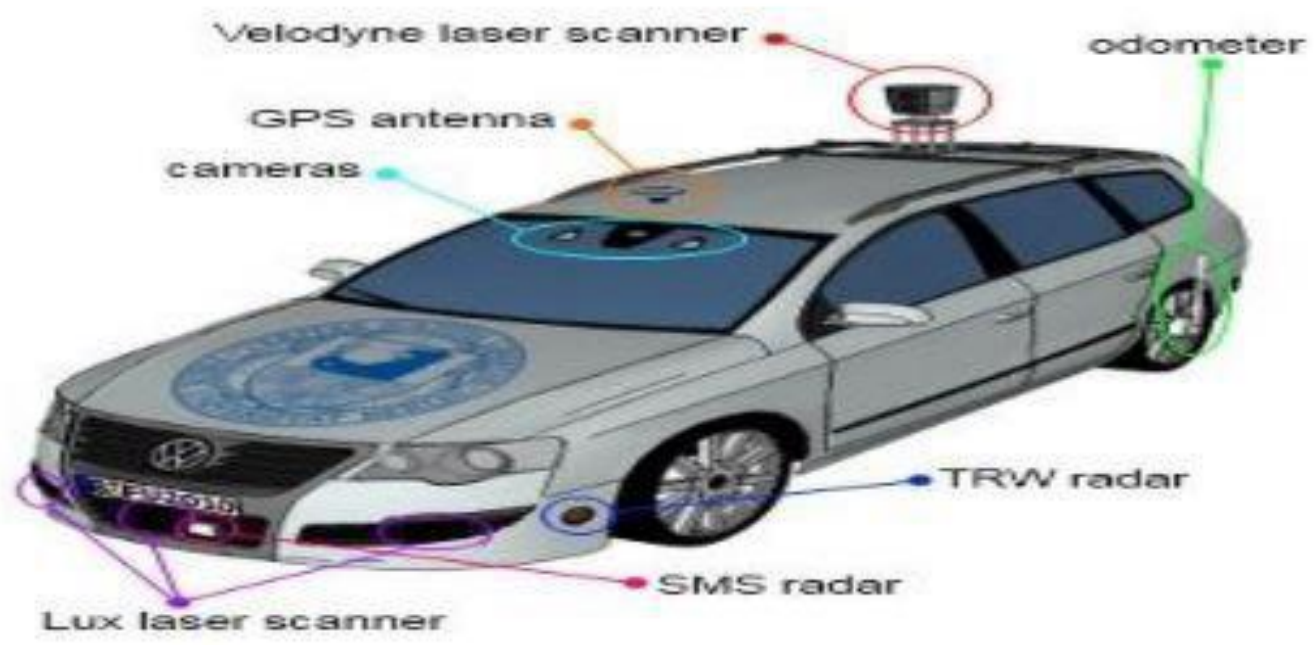

Figure 1: Basic Diagram of Autonomous Car

In spite of the fact that the models appear to be extremely fruitful, a completely independent auto that is sufficiently dependable to be in the city has not been built yet. This is for the most part a result of the troubles required in controlling a vehicle in the flighty activity states of urban regions. While better equipment is being created there are critical impediments on the counterfeit consciousness side of the examination.

\section{Literature Survey}

Tests have been directed on mechanizing autos since in any event the 1920s. The above figure clarifies the historical backdrop of an independent auto. How about we think about the present status of the self-sufficient auto.

In August 2013 Nissan declared its arrangements to dispatch a few driverless autos by 2020. Nissan introduced its self-sufficient auto innovation in a Nissan Leaf electric auto for showing purposes. The auto was exhibited at Nissan 360 test drive occasion held in California in August 2013. [2] 
Recent Advances in Communication, Electronics \& Electrical Engineering

In January 2014, Enlist Innovation's Navia carry turned into the principal self-driving vehicle to be accessible for business deal. Restricted to 12.5 miles for every hour $(20.1 \mathrm{~km} / \mathrm{h})$, the outdoors electric vehicle looks like a golf truck and seats up to eight individuals.

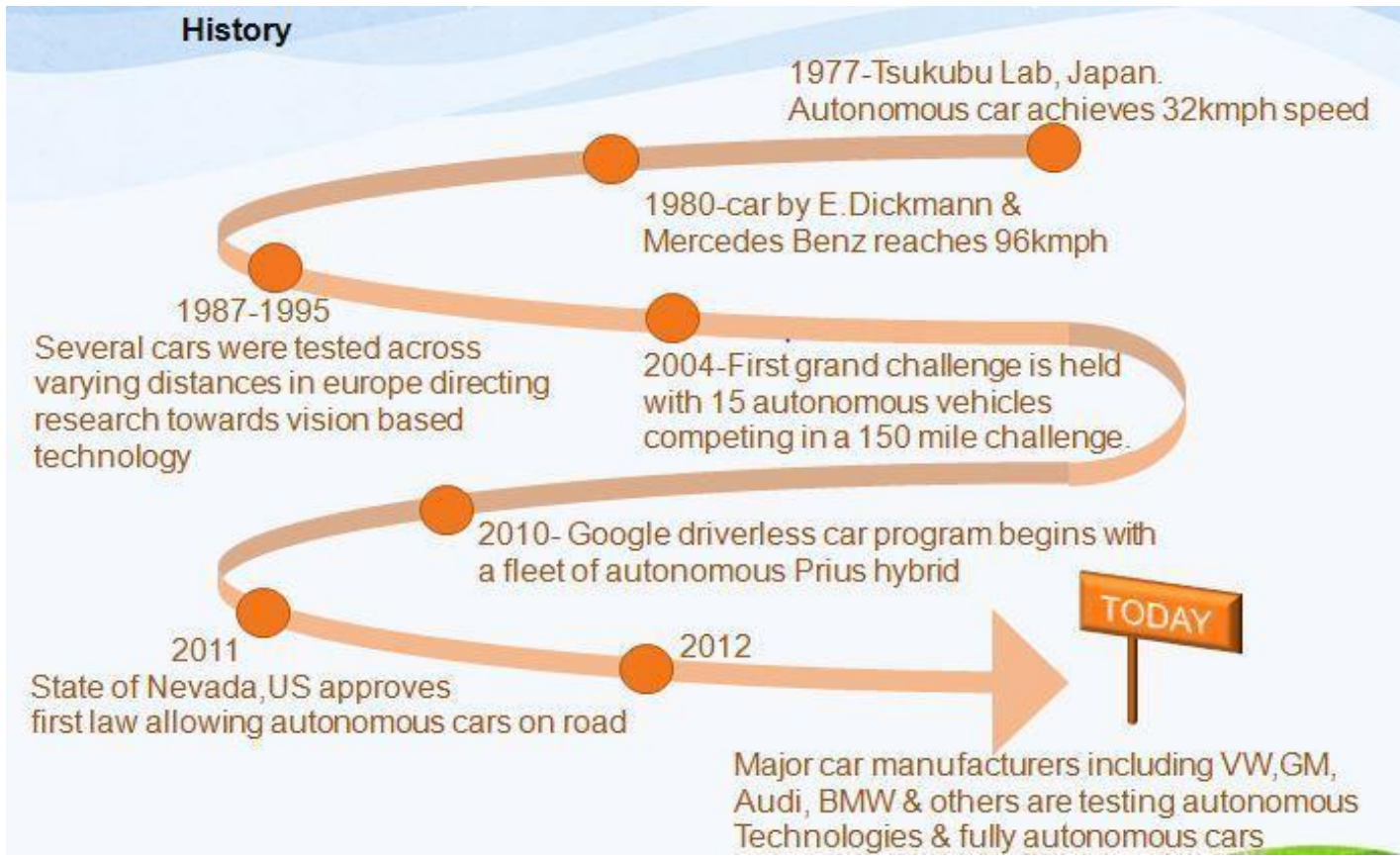

Figure 2: Literature Survey of Autonomous Car

In Walk 2015 Tesla Engines declared that it will present its Autopilot innovation by mid-2015 through a product refresh for the autos furnished with the frameworks that permit self-governing driving.

Beginning October 2016, all Tesla autos are worked with the fundamental equipment to permit full self-driving ability at a security level (SAE Level 5). The equipment incorporates eight encompass cameras and twelve ultrasonic sensors, notwithstanding the forward-confronting radar with improved preparing capacities. Full independence is just likely after a great many miles of testing, and endorsement by experts. Tesla Engines says it hopes to empower full selfdriving before the finish of 2017. [4]

\section{Sensor Technology}

The independent GPS-controlled auto will explore itself utilizing GPS-characterized waypoints. It will have the capacity to keep away from huge snags that may lay in its way by utilizing crash recognition and shirking framework inserted in the auto. The GPS framework will incorporate a GPS chip, GPS receiving wire, the processor and a GPS programming driver. The driver will enable the processor to speak with the GPS chip by means of serial correspondence to get condition information, for example, scope, longitude, elevation, speed, and heading. The receiving wire interfaces straightforwardly to the chip.[1] 
Recent Advances in Communication, Electronics \& Electrical Engineering

\section{LIDAR}

LIDAR (Light Discovery and Running) is a strategy for measuring separation by light. A light emission laser light (not hurtful to people) is discharged and might be reflected by a protest and come back to the sender, while its season of flight is measured. [6] So by knowing the speed of light, the question's separation to the reflector can be figured. The accompanying LIDARs are mounted on our model autos:

- The IBEO Lux (TM) laser scanner framework comprises of 6 individual sensors and a combination box. It looks $200 \mathrm{~m}$ around the vehicle.

- The IBEO Alasca (TM) laser scanner searches for impediments and is looking ahead up to $200 \mathrm{~m}$.

- The Debilitated LMS (TM) laser scanner takes a gander at the road control and distinguishes edges and path markings.

\section{RADAR}

RADAR (Radio Recognition and Extending) utilizes echoes of electromagnetic influxes of the radio range. Dissimilar to LIDAR, precise situating is impractical, in light of the fact that radio waves don't spread straight. The question's speed can be resolved utilizing the Doppler impact. In present day's auto have been coordinated with the accompanying sorts of RADAR's.

- The SMS (TM) radar is short-extend radar and works at $24 \mathrm{GHz}$. We combine the deterrents with the ones identified by the Lux LIDAR's.

- The Hella (TM) radar framework was initially created for the Volkswagen Phaeton and its uncommon utilize is to watch the neighbor paths.

- The TRW (TM) is our radar sensor with the longest range and it dependably recognizes different vehicles. It is urgent for quick driving on interstates.

\section{CAMERAS}

Utilized for path keeping and reinforcement help. The picture handling programming can distinguish path stripes, signs, stop lights, street signs and different articles. There are for the most part two sorts of cameras inherent the independent autos they are:

- Forward confronting HD shading camera: This camera is utilized to identify the articles introduce in the forward bearing.

- The side confronting HD shading camera: This camera is utilized to recognize the articles display on both the sides of the autos.

\section{Control Systems}

The techniques utilized for controlling the vehicle are separated into horizontal control and longitudinal control. The parallel controls concentrate on the guiding, while the longitudinal controls help with the speed control.[5] 
Recent Advances in Communication, Electronics \& Electrical Engineering

\section{Lateral Control}

A huge piece of the horizontal control is keeping the vehicle in its picked path and out and about. Current advancements are Path Takeoff Cautioning Frameworks (LDWS), and Path Keeping Help Frameworks (LKA). There is additionally another Parallel Stopping Help as of now accessible from some vehicle fabricates.

\section{Longitudinal Control}

Longitudinal control envelops the forward and switches headings of the vehicle. It has applications to control the speed of the vehicle and help the driver with forward and switch driving assignments. These applications incorporate back detecting to help with stopping, Versatile Journey Control (ACC), and pre-crash break help.

\section{Safety}

- Reduce road accidents by $90 \%$.

- 30000 fewer deaths.

- 2 million fewer injuries.

- 4.95 million fewer accidents.

\section{Impacts on Traffic}

- Less congested.

- Economic improvements.

- Reduction in time.

- Improvements in parking.

\section{Fuel Economy}

- Reduction of wasted Energy 90\%.

- Saving fuel.

- Effective speeding up \& braking.

- Improved Economy.

\section{Benefits and Limitations}

\begin{tabular}{|l|l|}
\hline \multicolumn{1}{|c|}{ BENEFITS } & \multicolumn{1}{c|}{ LIMITATIONS } \\
\hline Fewer traffic collision & Initial cost is more \\
\hline Elimination of redundant passengers & Maintenance is difficult \\
\hline Removal of constraints on occupants & $\begin{array}{l}\text { All the roads must be properly } \\
\text { painted/embedded with magnetic markers }\end{array}$ \\
\hline Improved fuel efficiency & Power consumption is more \\
\hline
\end{tabular}


Recent Advances in Communication, Electronics \& Electrical Engineering

\section{Future Scope}

Driving on streets will be much the same as surfing the Internet: there will be activity blockage however no wounds or fatalities. Propelled driver collaborator frameworks and new detecting innovations can be very advantageous, alongside the huge assortment of work on computerized vehicles. Along these lines, with the present and developing attention to the significance of security, reliable vehicle self-ruling frameworks can be sent in couple of years.

\section{Conclusion}

With the statures of the innovation self-sufficient auto is no more a myth. It's a reality! We might want to present that there must be further improvements in this innovation to make the independent auto more typical everywhere throughout the world. Because of speed control strategy, mischance free driving is conceivable and fuel savage is additionally made conceivable by the methods. In this paper, the study and audits of the current self-ruling auto testing were presented.

\section{References}

[1] Shuiying Wang, Steffen Heinrich, Miao Wang and Raul Rojas, "Shader-based Sensor Simulation for Autonomous Car Testing" 15th International IEEE Conference on Intelligent Transportation Systems Anchorage, Alaska, USA, September 16-19, 2012

[2] Nissan News, "Nissan says it will have first commercially-viable autonomous drive vehicles by 2020; across the range in 2 vehicle generations". Green Car Congress. Retrieved 2014-03-05.

[3] Maisto, Michelle,"Induct Now Selling Navia, First Self-Driving Commercial Vehicle". eWeek. Retrieved 7 January 2014.

[4] Lambert, Fred, "Tesla's software timeline for 'Enhanced Autopilot' transition means 'Full SelfDriving Capability' as early as next year". Electrek. Retrieved 2016-10-20.

[5] Qayum M.A, Siddique N.A, Haque M.A, Tayeen A.S.M. "Control of autonomous cars for intelligent transportation system". International Conference on Digital Object Identifier: 10.1109/ICIEV.2012.6317339 Publication Year: 2012, Page(s): 377 - 382.

[6] Matti Kutila; Pasi Pyykönen; Werner Ritter; Oliver Sawade; Bernd Schäufele m. "Automotive LIDAR sensor development scenarios for harsh weather conditions" 2016 IEEE 19th International Conference on Intelligent Transportation Systems (ITSC)

\footnotetext{
*Corresponding author.
}

E-mail address: smanasa702@gmail.com 